\title{
CORRIGENDUM
}

\section{Give Them Fish or Teach Them to Fish? The Effects of Stability of Social Stratification and Forms of Help on Higher Socioeconomic Status Group Members' Attitudes Towards Anti-Poverty Programs-CORRIGENDUM}

https://doi.org/10.1017/prp.2018.6, Published by Cambridge University Press, 23 March 2018

Keywords: poverty, socioeconomic status, intergroup helping, dependency, autonomy, corrigendum

The author apologizes for errors in the abstract and method (Ferolino 2018). The correct versions are given below:

\begin{abstract}
Building on social identity approach and intergroup helping as status relations model, the current research examined the effects of stability of social stratification and forms of help on higher socioeconomic status (SES) members' attitudes towards anti-poverty programs. Two studies were conducted in a 2 (social stratification stability) $\times 2$ (forms of help) design on willingness to support anti-poverty programs. Study 1 examined whether conditions of unstable and stable social stratification might yield pattern differences in support of hypothetical anti-poverty programs construed as dependency-oriented or autonomy-oriented help. Study 2 replicated and extended study 1 by examining higher SES (subjective) participants' attitudes towards the cash transfer programs (conditional vs. unconditional, which were determined by their perceptions of the stability of social stratification). Overall, the results of the two studies confirmed that attitudes towards anti-poverty programs could be construed as specific forms of help (dependency-oriented and/or autonomy-oriented help) depending on the nature of the intergroup relations (stability of the social stratification). Finally, the theoretical contribution of the current research is discussed.
\end{abstract}

\section{Method}

Participants and Design

Four items assessed dependency-oriented help $(\alpha=.89)$ : (a) 'I support a small increase of $0.5 \%$ in my taxes if the collected money would be allocated to programs that help high school students of low socioeconomic backgrounds receive loans to pay for the first year of college;' (b) 'I support a small increase of $0.5 \%$ in my taxes if the collected money would be allocated to programs that provide unemployed heads of low socioeconomic households contractual ( 5 months) or project-based jobs'; (c) 'I support a small increase of $0.5 \%$ in my taxes if the collected money would be allocated to programs that help sick members of low socioeconomic families pay for treatment in public hospitals'; (d) 'I support a small increase of .05\% in my taxes if the collected money would be allocated to programs that help low socioeconomic households get loans to pay for rent in a safe and affordable place'. Four items assessed autonomyoriented help ( $\alpha=.78$ ): (a) 'I support a small increase of $0.5 \%$ in my taxes if the collected money would be allocated to programs that help high school students of low socioeconomic backgrounds receive scholarships to attend good colleges in the country'; (b) 'I support a small increase of $0.5 \%$ in my taxes if the collected money would be allocated to programs that help unemployed heads of low socioeconomic households get trained and develop the necessary skills to start their own business'; (c) 'I support a small increase of $0.5 \%$ in my taxes if the collected money would be allocated to programs that help sick members of low socioeconomic households to become eligible and pay for health insurance to cover treatment in any hospitals'; (d) 'I support a small increase of .05\% in my taxes if the collected money would 
be allocated to programs that help low socioeconomic households get a loan to buy their own house in a safe and affordable area'.

\section{Reference}

Ferolino, A. (2018). Give Them Fish or Teach Them to Fish? The Effects of Stability of Social Stratification and Forms of Help on Higher Socioeconomic Status Group Members' Attitudes Towards Anti-Poverty Programs. Journal of Pacific Rim Psychology, 12, E16. doi:10.1017/prp.2018.6 